\title{
A prospective design of a social assistive electronic system for the elderly
}

\author{
Arsénio Reis ${ }^{*}$, Hugo Paredes ${ }^{1}$, Isabel Barroso ${ }^{2}$, Maria João Monteiro ${ }^{2}$, Vitor Rodrigues ${ }^{2}$, Salik Ram Khanal ${ }^{1}$, João Barroso ${ }^{1}$ \\ ${ }^{1}$ INESC TEC and Universidade de Trás-os-Montes e Alto Douro, Vila Real, Portugal \\ ${ }^{2}$ CIDESD and Universidade de Trás-os-Montes e Alto Douro, Vila Real, Portugal
}

A R T I C L E I N F O

Article history:

Received: 21 June, 2017

Accepted: 28 July, 2017

Online: 24 August, 2017

\section{Keywords:}

Wellbeing

Elderly

Ambient Assisted Living

Human Computer Interaction

\begin{abstract}
A B S T R A C T
Aging is a natural process that progressively introduces limitations in a person's life, which can have dramatic effects on the person's lifestyle and wellbeing and in most cases is related to the strength of the person's social bonds with the family and friends group. Therefore, it is important to maintain these bonds in the various stages of life, especially in the later life, when the individual has health limitations and may be living in a care centre. In this work, we developed an exploratory approach to the usage of ICT systems in order to autonomy assist the elderly in maintaining their social connections and relationships with family and friends. It doesn't substitutes the human care, but it should assist and encourage the elderly to preserve and develop their social activities and the relationships with their family and friends social group. We propose the design of a software system, capable of running in autonomous devices, such as, robots and other consumer appliances, enabling them to recognize and interact with the users, according to their state of mind and the specific current moment context. The interactions should be simple and focused on keeping the users engaged and informed about the current life events of their family and friends, and create the opportunities for the users to interact with the participants of those events by creating interaction proposals. On a technical level, the system should have knowledge about the user and be able to acquire and update context information from social media, video cameras, email, etc, regarding the user and the persons from his family and friends groups, in order to develop meaningful interactions with the user. An adaptive user interface would present and manage the interactions, acting as a mediator between the user and his family and friends group.
\end{abstract}

\section{Introduction}

This paper is an extension of a work originally presented in the 2017 International Conference on Technology and Innovation on Sports, Health and Wellbeing [1].

In Portugal, it was estimated that by 2016 there should be a ratio of three elderly people per youth and an average longevity of 81 years. In the last 2011 Census, this trend was confirmed, with a percentage of $19 \%$ of the population at or over 65 years old [2]. This increase longevity is a trend of the modern societies, from the second half of the twentieth century, which are facing a substantial growth of the aging population, conducting to new and relevant economic, social and political challenges

One of these challenges regards the sustainability of the health and social security systems, which have to deal with old and dependent people, living alone. In fact, about $60 \%$ of the elderlies

"Corresponding Author: Arsénio Reis, INESC TEC and Universidade de Trás-osMontes e Alto Douro, Vila Real, Portugal | Email: ars@utad.pt is living alone or in the exclusive company of other, also elderly people. The elderly dependency ratio has been increasing gradually and, in 2012, it was at $28.8 \%$, which corresponds to more than a quarter of the active population, and positions the elderly people in a category of individuals associated with isolation, loneliness, disease, poverty and even social exclusion [3][4].

In this context, the older people group is a social and economic vulnerable group, suffering from losses at the psychic and physical levels, which inevitably introduces modifications on their social relations and increases the risk of isolation and loneliness. On this regard, the World Assembly on Ageing under the theme "Society for all ages" refers to the importance of the full realization of the right of all people to enjoy the maximum physical and mental health [5].

To address these modifications and changes that occur in the family and in the individual's social interaction patterns, it is necessary to research alternative solutions for new models of 


\section{A. Reis et al. / Advances in Science, Technology and Engineering Systems Journal Vol. 2, No. 3, 1665-1669 (2017)}

aging, in which the individual retains emotional, physical, mental and social stability. This approach requires a new strategy for healthy aging, promoting intergenerational cooperation, community cohesion and social inclusion. During the aging process, the elderly individuals should maintain healthy social relationships in order to minimize psychological decline, which is particularly serious in age related institutionalized persons [6]. Becoming elder shouldn't introduce major changes in the individual's social role, otherwise, there will be great difficulties and the person, will struggle to adapt to the changes. Instead, the person should be active and engaged in stimulating activities [7].

Aging and the evolutions of the elderly's social roles is setting the tone for the development of specific devices and services that will support the user in the later phases of the aging process, particularly in regard to quality of life, maintaining social and family interactions, reducing the risk of loneliness and loss of social status in institutionalized elderly. Without detracting from the importance of the care, as provided by professionals and the value of humanized personal relationships, there is the need for additional aid, and the solutions based on social robotics are becoming a specialized technological branch, which can support the interactive dimension of the care process [8] [9]..

\section{Assisting social activity}

The process of an individual becoming older or aging encompassed physical, psychological and social changes. It is one of the highest risk factors known for most human diseases and it will introduce limitations to the individual life style [10]. The reduction in physical and social activity will rise these risk factors and degrades the aging process, causing or increasing suffering to the individual and to his family and friends [11]. Most times, the individual well-being is related to the strength of the social bonds with the family and friends group, so it is important to keep this bonds in the various stages of life, especially in the later life, when the individual has health limitations and is living in a community centre [12].

In a study regarding the older people active aging perception, the authors found that the most common perception were related to: maintaining physical health and functioning ( $43 \%$ ), leisure and social activities (34\%), mental functioning and activity $(18 \%)$ and social relationships and contacts (15\%) [13]. This study reveals that the maintenance of the social and mental activity accounts for the $57 \%$ of the perceive aging and is an important issue regarding successful aging and the Later Life or eight stage of life [14].

On another recent study, conducted on several Portuguese care centers, the users (elderlies) were interviewed regarding their motivation to use information and communication technologies (ICT), including artificial intelligent personal assistants as companions and assistive mediators. It was concluded that in this group, elderly people living in a care center, there is a strong will and open mind to try to use new technologies and new forms of interaction. In fact, this population is composed mostly by old people (more than 70 years old), suffering from some type of chronic disease and loneliness related problems (95\%). The health issues also manifest as disabilities $(75 \%)$, mostly causing mobility problems (53\%) and sight problems (40\%). The adoption of social robots or assistants would be welcome as well as other assistive technologies [15]. These conclusions were surprising, in the sense that the literature suggests that the usage of ICT by older adults is complex and extends beyond the dichotomy between 'successful users' and 'unsuccessful non-users' [16]. On closer look, the successful adoption of ICT solutions by older people is related to attitudes, experience of use, and perceived benefits [17], with many studies emphasizing the potential benefits of the use of ICT for elderly people, particularly by allowing them to stay connected to what is happening around them and to interact with others [18][19][20]. This interaction possibility is particularly important, if not dramatic, for people living in a care centre, which might explain the motivation to use ICT solutions.

The Ambient Assisted Living embraces the concept of helping senior citizens to improve their quality of life and expand their participation in the community by using systems to overcome their special needs, based on ubiquitous sensing, individualenvironment interaction, context awareness, and learning information systems [15]. The European overview report of Ambient Assisted Living (AAL) researches this concept and aims to find out an efficient solution to help these elderly people independently living [21]. The usage of ICT has been researched as a tool to support the therapeutic process, in which the main actors are the physicians [22]. The usage by the patients themselves is a new approach and requires the patient ability to properly use a system [23].

\section{Autonomous assistance in social activities}

This prospective proposal has the objective of design and implement a system to monitor and support users with age related limitations, in order to promote their daily well-being. Most times, these users are living in an institution and have health limitations affecting their social activity. They also have limitations on using modern information and communication based equipment. This systems aims to overcome those limitations by promoting and reinforcing the bonds between the user and the elements of his family and friends group, with the usage of information and communication technologies.

The software system should enable autonomous equipment to recognize and interact with the users, according to their state of mind and the specific momentary context. The main features should provide the ability to identify the users and have a set of interactions to inform the users about the everyday life of their family and friends group. It should promote interactions with them in order to mitigate the tendency for social isolation and its negative consequences.

Due to the user's limitations, the system's user interface should be designed by following the adaptive interfaces paradigm [24], in accordance with the user profile and the context. It should use simple interactions, based on natural language [25], in order to be user friendly to the expected age group.

The system is meant to be installed in autonomous equipment, such as autonomous robots or consumer appliances, and should be tested in elderly care institutions, such as social support centres, where users are admitted as residents. Specific testing plans should be designed as intervention plans suited to test the equipment and the software in order to evaluate their suitability and feedback the system development project [26].

This assistive system should forge a new type of relationship with the users by maximizing their social activity and maintenance of the relationship with their family and friends social group, which is often degraded due to the user's limitations and institutionalization. 


\section{Methods}

The teams working on the system development should have two distinct backgrounds: software engineering; and health care. The work should be done in short, interactive, cycles, in which the healthcare team should validate the requirements; verify the usability of the developed features; and test the features with real users. The software engineering team should develop the system using the state of the art technologies, following a user centric development method in order to meet all the usage requirements, related to the user's limitations [27][28][29][30].

The development and implementation of this system should have two main phases. A first phase, focused on software development and a second phase, focused on the field tests

In the first phase it should be designed and developed the system software, with the necessary features in order to accomplish the main objectives. The main areas of software development will be related to:

- Image acquisition and analysis, for the users identification and state of mind recognition;

- Application design with databases and social media APIs, for the development of the user activities;

- Natural langue and adaptive user interfaces, for the development of the system's user interface;

- Remote equipment management, for the planning and execution of the equipment deployment during the field tests.

The software development should be executed using agile methods in an incremental process. In this phase, the healthcare professionals should be part of the team in order to create the requirements and specifications as well as to monitor the development results.

On a second phase, the focus should be on the field tests and the monitoring of the system usage by the real users. Some development will still be necessary in order to adjust and develop some features, according to the users monitoring feedback. In this phase, a strong effort should be done to monitor the users in different usage contexts.

The autonomous equipment should be adapted for usage in the testing institutions, including the necessary adjustments for the remote management of the equipment.

\section{Requirements and features}

The system should provide a set of basic functionalities, features or requirements, related to the interaction with the users, namely: user identification; state of mind assessment; current context; personal information retrieval; a set of activity proposals.

The user identification and state of mind evaluation will be based on image acquisition and analysis, after which the system should retrieve the user profile and decide on an activity proposal. The activity proposal could be as simple as a personalized greeting or a more complex interaction, according to the current context and the user state of mind.

The context, personal information and state of mind, should include information about: gender, age, special needs, personal preferences, time of day, time of year, physical location, state of mind (sadness, joy, etc.), etc.
The interactions with the user should be developed as a set of activities that can be proposed and executed with the user. Figure 1 and Figure 2 have sequence diagrams illustrating two interactions. Some activities to be developed are: (1) Basic greeting; (2) Email management; (3) Social Network management; (4) Social and family events management; and (5) Social games.

- The basic greeting activity is a simple greeting interaction, in which the system greets the user according to the state of mind and context of the moment.

- The email management activity should provide a personal email box to each user and inform the user about the current messages status. In particular dates, such as family anniversaries, the system should offer the user a chance to send a congratulations message.

- The social media management is a more sophisticated activity in which the system monitors the user group of family and friends, regarding their activity in the social networks, e.g., facebook, twitter, Instagram, etc., and informs the user about relevant updates.

- The social games activity has the objective of adapt and create a set of social games, e.g., cards, trivia, etc., that the user can play in the system.

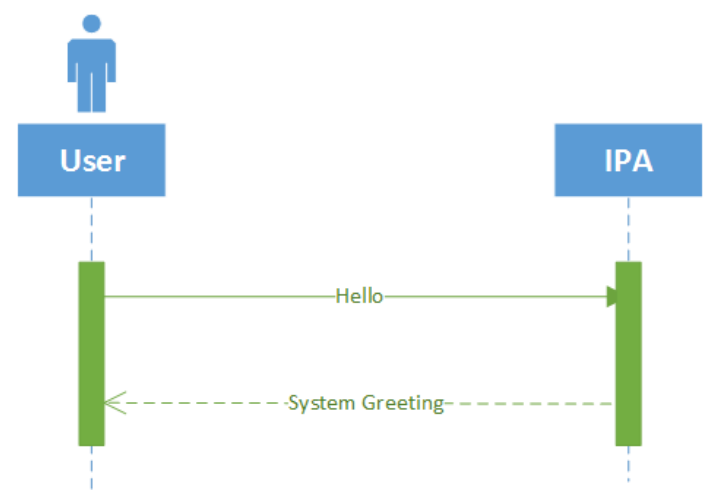

Figure 1 - Sequence diagram of basic greeting activity

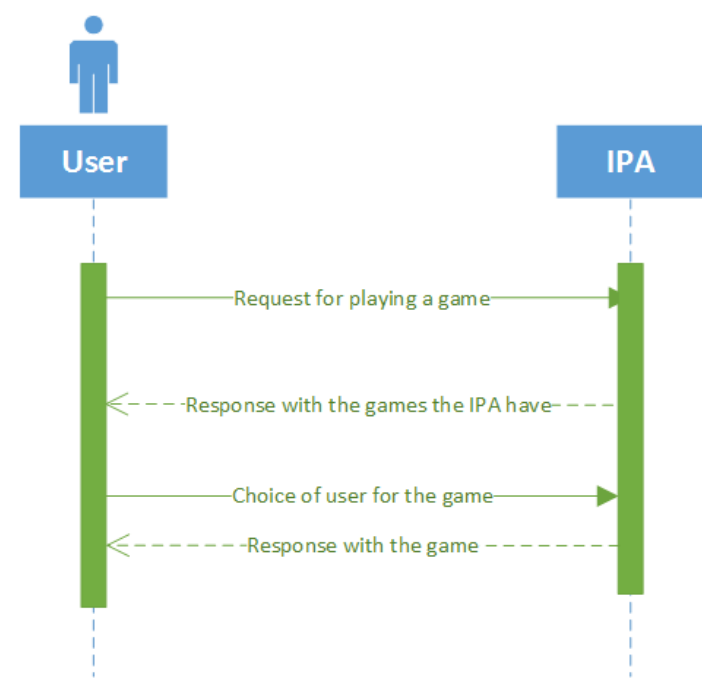

Figure 2 - Sequence diagram for social game activity.

The email and social media management are specially targeted to strengthen the user bonds with the elements of his family and friends. The user should be kept up to date with the course of lives of his friends and family and the systems should provide 


\section{A. Reis et al. / Advances in Science, Technology and Engineering Systems Journal Vol. 2, No. 3, 1665-1669 (2017)}

opportunities for the user to interact with those person on the social media networks. In Figure 3, it is described the basic workflow of an interaction with a user. As previously described, the system engages with the user and based on the available data about the user and the current context, it proposes an activity in order to forward an interaction.

The set of features should be extensively tested with real users in order to evaluate their tangible contribution to the main objective and their usability, considering the user interface and the user's limitations. So, a series of interventions plans should be created in order to test the system and the equipment in several real scenarios, together with partner institutions. For each intervention, a specific plan should be created, considering the specific conditions such as: the user's characteristics; the context of the hosting institution; the technical resources available.

\section{The current consumer electronic assistants}

Currently there are on the market several electronic assistants, e.g., Amazon Alexa, Google Assistant, Apple Siri, Microsoft Cortana, that are able to assist the user in some daily tasks. Some of this companies also provide hardware appliances uniquely designed to house their assistant software. In TABLE I are summarized the main features of this assistants.

Table I - Electronic assistants main features

\begin{tabular}{|c|c|c|c|c|}
\hline Interactions & $\begin{array}{c}\text { Google } \\
\text { Assistant }\end{array}$ & $\begin{array}{l}\text { Amazon } \\
\text { Alexa }\end{array}$ & $\begin{array}{l}\text { Apple } \\
\text { Siri }\end{array}$ & $\begin{array}{c}\text { Microsoft } \\
\text { Cortana }\end{array}$ \\
\hline Create a shopping list & yes & yes & no & no \\
\hline Check Calendar & yes & yes & yes & yes \\
\hline Manage Calendar & no & yes & yes & yes \\
\hline Check date and time & yes & yes & yes & yes \\
\hline Set an Alarm & yes & yes & yes & yes \\
\hline Check Weather & yes & yes & yes & yes \\
\hline Check Traffic & yes & yes & yes & yes \\
\hline Play news & yes & yes & no & no \\
\hline Play music & yes & yes & yes & yes \\
\hline Search Online & yes & yes & yes & yes \\
\hline Perform Calculations & yes & yes & yes & yes \\
\hline Call a Uber & no & yes & yes & no \\
\hline $\begin{array}{c}\text { Control home temperature } \\
\text { and lights }\end{array}$ & yes & yes & yes & no \\
\hline Lock/Unlock Doors & no & no & yes & no \\
\hline Play games & yes & yes & yes & yes \\
\hline Make a call & yes & yes & yes & yes \\
\hline Read books & no & yes & no & no \\
\hline Shopping on amazon & no & yes & no & no \\
\hline Order pizza & no & yes & yes & yes \\
\hline Manage SMS & yes & yes & yes & yes \\
\hline Read emails & no & no & yes & yes \\
\hline Send emails & no & no & yes & no \\
\hline Send posts in Facebook & yes & yes & yes & no \\
\hline Send posts in Twitter & yes & yes & yes & \\
\hline $\begin{array}{c}\text { Receive Facebook } \\
\text { notifications }\end{array}$ & no & no & no & no \\
\hline $\begin{array}{c}\text { Receive Twitter } \\
\text { notifications }\end{array}$ & no & no & no & no \\
\hline
\end{tabular}

It is a very promising set of interactions, but on some preliminary tests we concluded that there is a gap between what the assistants can do and what they effectively do when confronted with a user expecting to execute an interaction. We cannot categorically state that the assistants can't execute the actions, but effectively it would be very difficult for an elderly to use them in order to maintain some sort of social interaction with their friends and families. The preliminary testing suggest that these assistants lack the empathy and common sense engagement necessary to interact with an elderly. In future work we expect to measure the quality of the interaction and assess the effectiveness of the interaction.

\section{Conclusion}

In Figure 3 it is presented the general system workflow, regarding an autonomous user interaction. Although it is a simple workflow, the strict software implementation depends of a diverse set of concepts and technologies. The field tests and implementation, with real users in real institutions, are a main care endeavour and its constant feedback is determinant to the success of the system development.

\section{System Model}

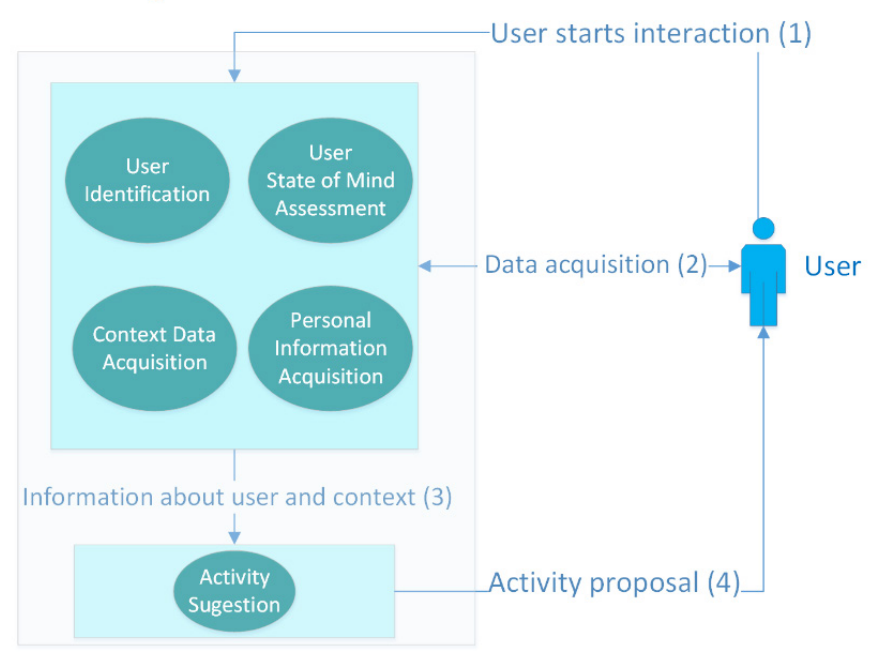

Figure 3 - System workflow

The success of this proposal is dependent of two main fiends of study: software engineering and elderly care. In such a sensible context, of elderly users with age related limitations, the subtle details of the system, in particular the user interface usability, are paramount and an excellent multidisciplinary team management is necessary. In TABLE I is summarized the features and the related research areas that the software system combines.

Table II - Features and research areas

\begin{tabular}{|l|l|}
\hline \multicolumn{1}{|c|}{ Features } & \multicolumn{1}{c|}{ Research areas } \\
\hline User identification & $\begin{array}{l}\text { Image processing (face } \\
\text { recognition) }\end{array}$ \\
\hline State of mind assessment & $\begin{array}{l}\text { Image processing (emotion } \\
\text { detection) }\end{array}$ \\
\hline Context acquisition & $\begin{array}{l}\text { On-line services APIs } \\
\text { Localization services } \\
\text { Image proecessing (Object } \\
\text { detection and recognition) }\end{array}$ \\
\hline Data retrieval & Databases \\
\hline Social media related activities & Social media APIs \\
\hline Social games & Gaming and Serious games \\
\hline Natural language user interface & $\begin{array}{l}\text { Adaptive interfaces } \\
\text { Natural language }\end{array}$ \\
\hline
\end{tabular}




\section{A. Reis et al. / Advances in Science, Technology and Engineering Systems Journal Vol. 2, No. 3, 1665-1669 (2017)}

The success of the features implementation must be assured by a user centric development with the continuous participation of the health care team elements. They should also act on behalf of the users in order to assure a user participated development.

This system proposal is intended for usage with autonomous systems such as robot devices, but it can be adapted and incorporated in other user appliances, such as settop tv boxes or even mobile phones. We didn't refer to a system architecture, but in a real system, with an extensive catalogue of user interactions and activities proposals, it should be considered the usage of a cloud backend implementation and a user device front end.

\section{Conflict of Interest}

The authors declare no conflict of interest.

\section{Acknowledgment}

This work was supported by Project "NanoSTIMA: Macro-toNano Human Sensing: Towards Integrated Multimodal Health Monitoring and Analytics/NORTE-01-0145-FEDER-000016" financed by the North Portugal Regional Operational Programme (NORTE 2020), under the PORTUGAL 2020 Partnership Agreement, and through the European Regional Development Fund (ERDF).

\section{References}

[1] Arsenio Reis, Hugo Paredes, Isabel Barroso, Maria Joao Monteiro, Vitor Rodrigues, Salik Ram Khanal, Joao Barroso: Autonomous systems to support social activity of elderly people a prospective approach to a system design. 2016 1st International Conference on Technology and Innovation in Sports, Health and Wellbeing (TISHW); 12/2016, DOI:10.1109/TISHW.2016.7847773

[2] Instituto Nacional de Estatística (2011). Censos 2011- Resultados Provisórios.

$\mathrm{http}: / /$ censos.ine.pt/xportal/xmain?xpid=CENSOS\&xpgid=ine_censos_publi cacao det\&contexto=pu\&PUBLICACOESpub boui $=122073978 \&$ PUBLIC ACOESmodo $=2 \&$ selTab $=$ tab1\&pcensos $=6196 \overline{9} 554$

[3] Instituto Nacional de Estatística (2012). O Envelhecimento em Portugal. Situação demográfica e socio-económica recente das pessoas idosas, Serviço de Estudos sobre a População do Departamento de Estatísticas Censitárias e da População.

[4] Fernandes, A. (2001). Velhice, solidariedades familiares e política social: itinerário de pesquisa em torno do aumento da esperança de vida. Sociologia, Problemas e Práticas [online], n.36, pp.39-52.

[5] Conselho Económico e Social (2013). Parecer de iniciativa sobre as consequências económicas, sociais e organizacionais decorrentes do envelhecimento da população. Lisboa:

[6] Palmer, A. D.; Newsom, J. \& Rook, K. (2016). How does difficulty communicating affect the social relationships of older adults? An exploration using data from a national survey. Journal of Communication Disorders, 62:131-146.

[7] Cabral, M. (coord.) (2013). Processos de Envelhecimento em Portugal. Lisboa: Fundação Francisco Manuel dos Santos.

[8] Reza K., Sima S., \& Mei-Tai Chu (2014). Socially Assistive Robots in Elderly Care: A Mixed-Method Systematic Literature Review. Intl. Journal of Human-Computer Interaction, 30: 369-393.

[9] Tânia Rocha, Hugo Fernandes, Arsénio Reis, Hugo Paredes, João Barroso: Assistive Platforms for the Visual Impaired: Bridging the Gap with the General Public. Recent Advances in Information Systems and Technologies, 03/2017: pages 602-608; , ISBN: 978-3-319-56537-8, DOI:10.1007/978-3319-56538-5_61

[10] Dillin, Andrew, Daniel E. Gottschling, and Thomas Nyström. "The good and the bad of being connected: the integrons of aging." Current opinion in cell biology26 (2014): 107-112.

[11] Rowe, J. W., \& Kahn, R. L. (1987). Human aging: usual and successful.Science, 237(4811), 143-149.
[12] Rook, K. S. (1984). The negative side of social interaction: impact on psychological well-being. Journal of personality and social psychology, 46(5), 1097.

[13] Bowling, A. (2008). Enhancing later life: how older people perceive active ageing?. Aging and Mental Health, 12(3), 293-301.

[14] Fisher, B. J. (1995). Successful aging, life satisfaction, and generativity in later life. The International Journal of Aging and Human Development, 41(3), 239-250.

[15] Sun, H., De Florio, V., Gui, N., \& Blondia, C. (2009, April). Promises and challenges of ambient assisted living systems. In Information Technology: New Generations, 2009. ITNG'09. Sixth International Conference on (pp. 1201-1207). Ieee.

[16] Selwyn, N., Gorard, S., Furlong, J., \& Madden, L. (2003). Older adults' use of information and communications technology in everyday life. Ageing and society, 23(05), 561-582.

[17] Arsénio Reis, Dennis Paulino, Hugo Paredes, João Barroso: Using Intelligent Personal Assistants to Strengthen the Elderlies' Social Bonds. Universal Access in Human-Computer Interaction. Human and Technological Environments, 01/2017: pages 593-602; , ISBN: 978-3-319-58699-1, DOI:10.1007/978-3-319-58700-4_48

[18] Hernández-Encuentra, E., Pousada, M., \& Gómez-Zúñiga, B. (2009). ICT and older people: Beyond usability. Educational Gerontology, 35(3), 226-245.

[19] Weatherall, J. W. A. (2000). A grounded theory analysis of older adults and information technology. Educational Gerontology, 26(4), 371-386.

[20] Magnusson , L. , Hanson , E. , Birto , L. ,Berthold , H. , Chambers , M. , \& Daly, T. ( 2002 ). Supporting family carers through the use of information and communication technology - the EU project ACTION . International Journal of Nursing Studies , 39, 369-381 .

[21] Steg, H., \& Strese, H. (2005). Ambient assisted living-european overview report.

[22] Reis, A., Lains, J., Paredes, H., Filipe, V., Abrantes, C., Ferreira, F., . . . Barroso, J. (2016). Developing a System for Post-Stroke Rehabilitation: An Exergames Approach. In M. Antona \& C. Stephanidis (Eds.), Universal Access in Human-Computer Interaction. Users and Context Diversity: 10th International Conference, UAHCI 2016, Held as Part of HCI International 2016, Toronto, ON, Canada, July 17-22, 2016, Proceedings, Part III (pp. $403-$ 413). Cham: Springer International Publishing.

[23] Paredes, H., Reis, A., Marinho, S., Lains, J., Filipe, V., \& Barroso, J. (2016) A study of ICT active monitoring adoption in stroke rehabilitation Proceedings of the 3rd IPLeiria's International Health Congress. BMC Health Services Research, 16(3), 111-242. doi: 10.1186/s12913-016-1423-5.

[24] Sa-nga-ngam , P. , \& Kurniawan , S. ( 2006). An investigation into older people's browsing activities. Psychology Journal , 4 ( 3 ), 245 - 265.

[25] Bobillier Chaumon, M. E., Michel, C., Tarpin Bernard, F., \& Croisile, B. (2014). Can ICT improve the quality of life of elderly adults living in residential home care units? From actual impacts to hidden artefacts. Behaviour \& Information Technology, 33(6), 574-590.

[26] Arsénio Reis, Isabel Barroso, Maria João Monteiro, Salik Khanal, Vitor Rodrigues, Vitor Filipe, Hugo Paredes, João Barroso: Designing Autonomous Systems Interactions with Elderly People. Universal Access in HumanComputer Interaction. Human and Technological Environments, 01/2017: pages 603-611; , ISBN: 978-3-319-58699-1, DOI:10.1007/978-3-319-587004_49

[27] Jameson, A. (2009). Adaptive interfaces and agents. Human-Computer Interaction: Design Issues, Solutions, and Applications, 105, 105-130.

[28] Liddy, E. D., Paik, W., McKenna, M. E., Weiner, M. L., Edmund, S. Y., Diamond, T. G., ... \& Snyder, D. L. (2000). U.S. Patent No. 6,026,388 Washington, DC: U.S. Patent and Trademark Office.

[29] Gulliksen, J., Göransson, B., Boivie, I., Blomkvist, S., Persson, J., \& Cajander, A. (2003). Key principles for user-centred systems design. Behaviour and Information Technology, 22(6), 397-409.

[30] Beck, K., Beedle, M., Van Bennekum, A., Cockburn, A., Cunningham, W., Fowler, M., ... \& Kern, J. (2001). Manifesto for agile software development. 